\title{
REDACCIÓN DE LA CONSTITUCIÓN EN CLAVE NO MASCULINA
}

\author{
ANTONIO TORRES DEL MORAL
}


SUMARIO

1. INTRODUCCIÓN. 2. DERECHO Y LENGUAJE. 3. APLICACIÓN A LA CONSTITUCIÓN. 4. PREÁMBULO. 5. TÍTULO PRELIMINAR. 6. TÍTULO I: DE LOS DERECHOS Y DEBERES FUNDAMENTALES: 6.1 Capítulo I: De los españoles y los extranjeros. 6.2 Capítulo II: Derechos y libertades: 6.2.1 Artículo 14. 6.2.2 Sección 1. ${ }^{a}$ : De los derechos fundamentales y de las libertades públicas. 


\title{
REDACCIÓN DE LA CONSTITUCIÓN EN CLAVE NO MASCULINA
}

\author{
ANTONIO TORRES DEL MORAL* \\ Catedrático de Derecho Constitucional
}

\section{INTRODUCCIÓN}

Expongo en estas páginas unas primeras reflexiones sobre una materia tan delicada como de plena actualidad desde hace ya algunos años, al menos desde principios de siglo y de milenio. Y lo hago con la plena seguridad de que sus posibles lectores tendrán recorrido más camino que yo en este asunto y con un mayor grado de implicación que el mostrado por mi hasta ahora en esta causa. Espero, sin embargo, no ser considerado temerario al tomar la decisión de publicarlas.

Seguramente el lenguaje (no en el sentido de emisión de signos más o menos captados por otro, sino en el sentido de un sistema codificado de signos, conceptos y palabras que los definen) no fue, precisamente por su complejidad, el primer modo de comunicación ${ }^{1}$, pero sí fue y sigue siendo el más importante. Para Saussure, la lengua es un sistema cuyas partes «pueden y deben ser consideradas en su solidaridad sincrónica». Es ilusorio, añade, «considerar un término simplemente como la unión de un determinado sonido con un determinado concepto. Definirlo así sería aislarlo del sistema del que forma parte» ${ }^{2}$.

\footnotetext{
* Catedrático de Derecho Constitucional. Facultad de Derecho. Universidad Nacional de Educación a Distancia. Obispo Trejo, 2. 28040 Madrid. Email: atorres@der.uned.es

1 Cfr. Birdwnistell, R. L.; «Comunicación», en Dsills, D. L. (dir.) (1974): Enciclopedia de las Ciencias Sociales, edic. esp. Aguilar, Madrid, vol. 2, pp. 559 y ss.

2 Saussure, F. de (1995): Cours de linguistique générale, Payot, París, pp. 124 y 157.
} 
Ese sistema lingüístico se inscribe en un sistema social asentado en una cultura. Cultura y sociedad son términos inescindibles, recíprocamente referentes ${ }^{3}$. En sentido convergente con el autor anteriormente citado, Gerth y Mills sostienen que, «[c]uando un símbolo dado significa lo mismo para un grupo de personas, podemos decir que estas personas constituyen una comunidad de discurso», en cuyo seno la función principal del lenguaje es precisamente coordinar la conducta social ${ }^{4}$. Y es un valor comúnmente admitido en Sociología, al menos desde Parsons, que en todo sistema social existen unas pautas culturales que actúan como vehículo de otros prerrequisitos funcionales del conjunto ${ }^{5}$.

Para Ferrater Mora, el lenguaje es sin duda uno de los elementos constitutivos de la realidad social e histórica humana. Se puede clasificar desde diversos puntos de vista. En nuestro caso interesa la distinción entre lenguaje indicativo y prescriptivo o normativo, pudiendo subdividirse el segundo en imperativo y valorativo $^{6}$. A una clasificación similar o parcialmente convergente se llega desde el campo de la semiótica, que distingue entre discursos enunciativos, argumentativos y ordenativos o deónticos ${ }^{7}$. Ciertamente de todos ellos cabe ver muestras en la Constitución española.

Algunas consideraciones sobre el lenguaje pueden apreciarse en los filósofos presocráticos, desde luego en los sofistas además de en Platón y Aristóteles, y más tarde en los estoicos; en la discusión medieval de los universales; en la filosofía racionalista y mucho más en la empirista (Hobbes, Locke, Berkeley y Hume) que puso de relieve su importancia como instrumento del pensamiento aunque sometiéndolo a crítica para no caer en sus trampas. Pero ha sido en el siglo Xx cuando más se ha cultivado el lenguaje como una cuestión central, si no la única, de la filosofía ${ }^{8}$, lo que se hace muy evidente en la corriente analítica anglosajona, cuyo tratamiento de la Ética consiste primordialmente en un análisis del lenguaje empleado en ella.

El lenguaje es un complejo de formas regladas según el ámbito o aspecto del lenguaje que se esté empleando, pues no son idénticas a la hora de dar órdenes y

3 Cfr. mi trabajo «Derecho a la cultura y fomento de la ciencia», en Alzaga Villaamil, O. (1984); Comentarios a las Leyes Políticas: Constitución Española de 1978, Edersa, Madrid, t. IV, pp. 197 y ss.

${ }^{4}$ Gerth, H., y Wright Mills, C. (1963), Carácter y estructura social, edic. esp., Paidos, Buenos Aires, pp. 93-94.

5 Parsons, T. (1966), El sistema social, edic. esp., Revista de Occidente, Madrid, p. 46.

${ }^{6}$ Cfr. Ferrater Mora, J. (1979), Diccionario de Filosofía, Alianza Editorial, Madrid, voz «Lenguaje», vol. 3, pp. 1937 y 1941.

7 Ibidem, voz «Discurso», vol. 1, p. 844.

8 Ibidem, voz «Lenguaje», ob. cit., vol 3, pp. 1938-1941. 
obedecerlas que en la descripción de un objeto, para preguntar, para agradecer o a la hora de hacer un chiste 9 . Por eso, como advierte Rocher, aunque «entre los conceptos y el lenguaje, el vínculo es estrecho y constante», a veces esa relación resulta equívoca porque el lenguaje, «al tiempo que evoca una realidad, la enmascara», o la deforma, y de ahí proceden los errores en la comunicación ${ }^{10}$. En el texto fundamental español, según veremos, también hay errores y enunciados que inducen al error.

\section{DERECHO Y LENGUAJE}

Llevando estas consideraciones iniciales al campo jurídico, anota Ribas Alba que fue Vico quien, con su doctrina, de origen platónico, sobre la lengua muda primordial, puso de relieve la semejanza estructural entre lenguaje y Derecho ${ }^{11}$. Porque, en efecto, el lenguaje y el Derecho procuran ordenar la realidad humana; cada uno de ellos de una forma distinta, pero el principio de orden que late en ambos sistemas es el mismo: uno y otro pueden ser utilizados para reforzar la realidad, o para alterarla o para transformarla; «cabe hablar, por tanto, de una juridicidad inmanente en el lenguaje» ${ }^{12}$.

En este mismo orden de consideraciones, Hernández-Gil escribió: «[e]l Derecho es en función de la lengua (...) la ley en su acepción jurídica surge con o como lenguaje», antes de que hubiera escritura. La asociación entre ambos es tal que el Derecho es lenguaje porque «inicia su existencia a partir de él... [y] se nos muestra siempre en mensajes lingüísticos» ${ }^{13}$.

Por eso se dice con suma verdad que el buen Derecho exige un buen lenguaje y más en un Estado, como el español, que, además de ser social y democrático de Derecho, pretende ser también un Estado de cultura ${ }^{14}$, aunque este sintagma no forma parte de la definición del régimen político que hace el primer precepto de nuestra Constitución. Ahora bien, acaso haya cierta coincidencia entre juristas sobre qué es un buen Derecho, pero seguramente discrepemos un tanto sobre qué es un buen lenguaje.

9 Ibidem, voz «Lenguaje (juegos de)», ob. y vol. cits., p. 1945.

10 Rocher, G. (1973), Introducción a la Sociología General, edic. esp., Herder, Barcelona, pp. 91-92.

11 Ribas Alba, J. M.' (2015), Prehistoria del Derecho, Almuzara, S. L., p. 33.

12 Ibidem, pp. 37-41.

13 Hernández-Gil, A. (1975), El abogado y el conocimiento jurídico, Madrid, pp. 11-12, y (1982). El cambio político español y la Constitución, Planeta, Barcelona, pp. 338-340, de donde he tomado la cita de la obra anterior.

14 Cfr. Prieto de Pedro, J. (2000), «Lenguaje jurídico y Estado de Derecho», Revista de la Administración Pública, Madrid, n. ${ }^{\circ} 140$, p. 111. 
Aun así, podemos actuar por aproximación: un buen lenguaje es uno que no sea muy técnico, pero tampoco vulgar. No puede faltarle cierta precisión para decir bien lo que se quiere decir, pero debe ser distinto de lo que se conoce como sociolecto, es decir, un dialecto propio de un grupo social; dicho llanamente una jerga de especialistas. Porque, invirtiendo el anterior argumento de que estamos en un Estado de cultura, no podemos perder de vista que es también y principalmente un Estado democrático, al cual repugna un ordenamiento jurídico intelectualmente inalcanzable para el común de la ciudadanía ${ }^{15}$.

Quizá todo pueda resumirse en hablar y escribir con claridad y distinción, dicho con frase cartesiana bien conocida. Ese es precisamente el dictamen final de Hernández-Gil: el carácter más apreciable del lenguaje jurídico es la claridad; la ley no tiene que persuadir, pero sí tiene que ser necesariamente clara, accesible al conocimiento ${ }^{16}$. Cometido nada fácil, de todos modos, porque el Derecho toca fibras sensibles, nada menos que nuestras vida, libertad y propiedad, por decirlo en términos de lockianos, y eso hace que a veces se venza indebidamente de un lado o de otro. Por eso, como toda obra humana, sea individual o comunitaria, ni el lenguaje común ni el lenguaje jurídico son asépticos, «inocentes», sino productos sociales tributarios de la cultura hegemónica en cada tiempo y lugar, y también, por tanto, de los intereses, las fuerzas, los conflictos y los consensos.

Estamos, pues, inmersos en un terreno en el que son inesquivables los valores. Dice a este respecto M. A. Quintanilla que, suponiendo que los usos lingüísticos estén de alguna forma regulados por normas y dependan, por lo tanto, de valores, esto nos llevará rápidamente a admitir que, en último término, los significados dependen de tales valores ${ }^{17}$. De ahí la dificultad de emplear un lenguaje axiológicamente neutral; no lo es, desde luego, el lenguaje moral y menos aún el jurídico, sobre todo en el ámbito constitucional.

Basta con echar una ojeada a nuestros textos constitucionales históricos para ver algunas frases y locuciones tributarias de la cultura española decimonónica: a) las circunscripciones electorales eran delimitadas con la proporción de un diputado cada equis almas ${ }^{18}$, que no personas ni habitantes; b) invariablemente, en el sistema sucesorio a la Corona, se otorgaba preferencia al varón sobre la

15 Ibidem, p. 116 y 119.

16 Hernández-Gil, A. (1975), El cambio político español y la Constitución, ob. cit., pp. 342 y $345-346$.

17 Quintanilla, M. A. (1979), Voz «Ciencia», en Diccionario de Filosofía Contemporánea, obra dirigida por él mismo, Sígueme, Salamanca, p. 74.

18 Constitución de 1837: artículo 21; de 1845: artículo 20; texto nonato de 1856: artículo 24; Constitución de 1869: artículo 65; Proyecto constitucional de 1873: artículo 51; Constitución de 1876: artículo 27. Todavía se dice en el lenguaje popular «allí no había ningún alma». 
bembra $^{19}$ (término hoy unánimemente repudiado para designar personas del género femenino) salvo en el documento aconstitucional de Bayona, cuyo artículo 2. ${ }^{\circ}$ la excluía perpetuamente.

Aun con precedentes políticos y teóricos importantes (movimiento femenino de la Revolución Francesa, Condorcet, J. S. Mill...), a fines de la Primera Guerra Mundial se fue gestando una corriente de pensamiento y de actitud política favorable a la presencia y protagonismo de la mujer tanto social y cultural como jurídico y político, muy limitados por entonces. Contribuyó a ello el importante papel que jugó la mujer durante dicha contienda. Uno de los resultados fue el reconocimiento de su derecho de sufragio, que ya había tenido una implantación dispersa en América. En España aconteció, no sin resistencias, en las Cortes Constituyentes de la Segunda República, en tanto que en el Reino Unido hubo que esperar hasta 1949, de nuevo tras una guerra mundial. (Hegel habría aprovechado estos datos para confirmar su tesis sobre la guerra como partera de la Historia.)

Actualmente no hay Estado democrático alguno que vete la participación política del $50 \%$ de la población en forma de sufragio no ya solo activo, sino también pasivo, con su correlato de la presencia de la mujer en las Cámaras parlamentarias y en los Ayuntamientos.

Ello ha favorecido la práctica de nombrar los dos géneros cuando un orador se dirige a las personas que lo escuchan, práctica que se extendió a los programas radiofónicos y televisivos, y finalmente, aunque todavía no al completo, a los medios escritos. Es una manera, se dice, de romper con la invisibilidad de la mujer en todas estas parcelas de la vida social. Naturalmente, han sido las propias mujeres las que más, desde antes, y más lejos han actuado en este terreno, obteniendo un éxito notable.

Ahora bien, si, como se ha dicho argumentadamente, el cambio producido en los países occidentales desde el origen de la contemporaneidad hasta la segunda posguerra mundial fue mayor que el habido en los cuarenta siglos anteriores, no menos cierto es que el producido desde mediado el siglo xx hasta nuestros días (incluso, dentro de esta etapa, en los últimos 30 años) es, a su vez, más acelerado que el antes indicado. Y resultaría absurdo pensar que esta aceleración histórica no iba a afectar al mundo jurídico y político, precisamente dos ámbitos

19 Constituciones de 1837: artículo 51; de 1845: artículo 50; texto nonato de 1856: artículo 56; Constitución de 1869: artículo 77; de 1876: artículo 59; Ley de Sucesión en la Jefatura del Estado (1947) aconstitucional: artículo 11. I. La Constitución vigente, artículo 57.1, en línea con los modos y usos de su tiempo, corrigió esta desafortunada terminología pero no el injusto principio de varonía, que circunstancias políticas de nuestro país han impedido modificar pese a que existe un juicio casi unánime a favor de la igualdad sucesoria. 
(o uno solo en ocasiones) extraordinariamente sensibles a los cambios culturales, económicos, sociales, energéticos y tecnológicos. El Derecho tiene que dar cuenta de ello, y la política, facilitarlo.

\section{Género y sexo; lengua y uso de la lengua}

Según el Diccionario de la Real Academia Española, el género es una categoría gramatical; el sexo, es una condición orgánica, masculina y femenina, de animales y plantas; hace referencia a rasgos bioquímicos, fisiológicos y orgánicos. Pues bien, como apunta la profesora Lledó, acaso la autora más acreditada en esta materia, las lenguas románicas tienen flexión de género; dicho de otro modo, los sustantivos, los adjetivos, etc., varían según la categoría gramatical del género. El inglés y, con él, el 85 por 100 de las lenguas del mundo no la tienen ${ }^{20}$.

Por eso, durante siglos, para hacer referencia a grupos de personas de uno u otro sexo sin necesidad de duplicar los términos, se han utilizado masculinos con valor genérico, los cuales silencian frecuentemente a las mujeres.

Por otra parte, la citada autora, nos llama la atención sobre la diferencia entre lengua y usos de la lengua: «La lengua es un sistema de comunicación libre de sesgos ideológicos... Otra cosa bien distinta son los usos de la lengua — modificables, por tanto...- que suelen teñir los discursos».

Para ejemplificarlo, recoge dos episodios narrados en los medios de comunicación $^{21}$. Distinción sutil, porque la lengua es un instrumento de comunicación humana mediante la palabra. Por tanto, los sesgos ideológicos, los dobles sentidos, el uso irónico de los términos, etcétera, están en la lengua, a disposición del talento poético, satírico, sarcástico, injurioso o calumniador de

${ }^{20}$ Cfr. Guía para el uso no sexista de lenguaje, Servicio de Publicaciones de la Universidad Autónoma de Barcelona, 2011, p. 5.

21 El primero es una noticia leída en televisión sobre la visita a España de la señora Benazir Bhutto: «... la primer ministra dio en todo momento muestras de inteligencia y simpatía». Y lo comenta: «Como vemos en este ejemplo, el sexismo es solo atribuible a la mente de quien redactó tan peregrina noticia, nada en la lengua obliga a usar una frase como ésta». El segundo, un comentario hecho por el portavoz del Gobierno con ocasión del decimoctavo aniversario de la Constitución: «... si fuera chica se pondría (o la pondrían) de largo, si fuera ciudadano iría a votar». Las personas que lo criticaron de utilizar una lengua sexista no iban bien encaminadas, dice la Pfra. Lledó: el sexismo no estaba en la lengua, sino en las ideas del portavoz (Lledó Cunill, E.: «Lenguaje jurídico y género», ponencia presentada en el coloquio sobre Importancia del uso del lenguaje en el Derecho. Las palabras y las leyes, pp. 1-3.). Disponible en: http://www.eulalialledo.cat/wp-content/ uploads/2017/02/2011GPonenciaEulaliaLledoTXT.pdf 
quien la utiliza; las palabras (asesino, maestro, madre, dictador) tienen su significado independiente del buen o mal uso que de ella se haga; la lengua las brinda para quien quiera usarlas, y es su usuario quien elige el significado, si tiene varios, y el tono con que lo utiliza (Lázaro Carreter) para comunicar lo que quiere.

La distinción, además, es bien relevante en el problema que tratamos porque los usos de la lengua son cambiables, de manera que no hay que esperar a cambiar el idioma para encontrarle solución, sino que basta con mejorar sus usos.

Por eso, los usos actuales de la lengua deben reflejar la vocación igualitaria de nuestra sociedad haciendo visibles a las mujeres, para lo cual se deben encontrar alternativas al tradicional, ideológico y discriminatorio lenguaje masculino.

El lenguaje jurídico, hasta ahora, ha seguido un patrón masculino, sobre todo cuando se emplea el plural (los españoles, los diputados, los padres, todos...), pero también cuando se utiliza el singular (asistencia de abogado, juez ordinario, profesor, médico forense...).

Ha sido recientemente cuando este tipo de lenguaje y su impugnación adquirieron la categoría de problema jurídico, y algo más que jurídico, motivado por la emergencia de una beligerante corriente de pensamiento y de actitud en contra de la discriminación femenina que se ha hecho hasta hace bien poco del uso del idioma, de todos los idiomas españoles, y aun de todos los idiomas romances, a la hora de regular jurídicamente cualquier materia en la que tenga que utilizar términos relativos al sexo de los destinatarios o afectados por la norma. Porque, si durante varios milenios el varón ha dominado económica, social, jurídica y políticamente, es bastante lógico que ese dominio se haya reflejado no solo en la titularidad de los cargos públicos, sino también en los oficios y en el idioma. Pero ahora es otra cosa.

Ciertamente, durante mucho tiempo y con excepciones conocidas, apenas ha habido mujeres u organizaciones sólidas de mujeres fuertemente reivindicativas en este ámbito. Pero entra también dentro de la normalidad que, si ahora la Universidad y la judicatura arrojan una mayoría femenina y en la ingeniería y en la medicina se acortan las distancias, por poner solo algunos ejemplos, se reivindique que este cambio se vea reflejado en el importante vehículo del idioma.

Lo lógico era que el Derecho no permaneciera ajeno al fenómeno y diera cuenta de ello. Por eso los recientes movimientos feministas han venido reclamando intensamente la igualdad en el uso de la lengua también en el mundo jurídico y han impregnado de este espíritu a partidos políticos y sindicatos, así como a juristas masculinos sensibles a estas aspiraciones. Los cambios habían de 
afectar a los discursos políticos y a las declaraciones públicas, pero también a la legislación, a la Administración y a la Justicia.

Algo que ya ha comenzado a hacerse en ciertos ámbitos jurídicos, como el administrativo, el que más intensamente relaciona al poder público con el ciudadano, así como en la regulación del matrimonio y familia, en la redacción de contratos, etcétera:

- El Ministerio para las Administraciones Públicas editó, ya en 1990, un documento sobre el uso no sexista del lenguaje administrativo y la Ley de la Igualdad, de 2007, significó una buena cobertura para hacerlo.

- El Plan Estratégico de Igualdad de Oportunidades 2008-2011, aprobado en 2007 por el Gobierno de España, recoge recomendaciones de lenguaje no sexista.

- Muchas Administraciones autonómicas y locales han aprobado medidas y normas formuladas en lenguaje no sexista ni androcéntrico.

- Las leyes de igualdad y los planes de acción abogan por utilizar un lenguaje no sexista en todos los ámbitos de la sociedad ${ }^{22}$.

Ahora bien, si difícil es ganar esta batalla, más aún lo es hacerlo a corto plazo, por lo que resulta recomendable emplear mucho trabajo y mucha paciencia porque al tren del futuro, que ya ha partido de la estación de origen con un rumbo fijo, parece que avanza sin mucha prisa.

Distinguen la profesora Lledó entre sexismo y androcentrismo del idioma. El sexismo, dice la citada autora, es una actitud de menosprecio y desvalorización, por exceso o por defecto, de lo que son y hacen las mujeres; está basado en la hegemonía de los nombres y en todas las creencias que la respaldan y legitiman; en los textos sexistas aparece la mujer habitualmente desvalorizada, minimizada. El androcentrismo consiste en «una percepción centrada y basada en normas masculinas... Es sobre todo una perspectiva... una determinada y parcial visión del mundo que considera que lo que ha logrado la especie humana lo han realizado los hombres... que lo que es bueno para los hombres es bueno para la humanidad... Es considerar que los hombres son... el patrón para medir a cualquier persona... Así... en mayor medida que el sexismo... es la causa y el origen de unos determinados usos de la lengua que tienden a excluir o invisibilizar a las mujeres»; cuando se dice, por ejemplo, «los profesores dan clase», el masculino

22 La profesora Lledó, en la Guía, ya citada de la Universidad Autónoma de Barcelona, pone un curioso ejemplo: la Ley de Cooperación Internacional para el Desarrollo está muy bien redactada en lenguaje no sexista salvo al final, en su fórmula de Promulgación: «A todos los que la presente vieren y entendieren...» 
genérico «los profesores» silencia a la mujer ${ }^{23}$. El sexismo maltrata a la mujer; el androcentrismo la silencia. Puede comprobarse en frases y expresiones tan universalmente utilizadas como la Declaración de Derechos del Hombre y del Ciudadano y en el sufragio universal ${ }^{24}$. En la primera, la mujer estaba incluida pero silenciada ${ }^{25}$, y la segunda parece incluir a la mujer, pero encubre que el sufragio tuvo durante mucho tiempo como único sujeto al hombre.

Ahora bien, hemos de tener presente, en segundo término, que el idioma es un ser vivo. Las palabras, como también los giros lingüísticos, nacen y mueren; hay palabras vivas, nuevas, viejas, moribundas, muertas, recuperadas, de ida y vuelta de América (como algunos cantes flamencos); modismos cántabros, extremeños, peruanos y argentinos; galicismos y anglicismos, que hasta ahora se denominaban barbarismos, expresión que también debe ser eliminada porque, aunque tiene explicación histórica, hoy es pura sinrazón. Y, como tal ser vivo, el lenguaje está dotado de anticuerpos que rechazan los elementos extraños o que se lo parecen. Por eso, resulta escasamente recomendable someter a las personas del común a fuertes dosis de lenguaje feminista porque esta estrategia puede provocar más cansancio que convicción; incluso puede originar rechazo. En esta batalla no se trata de vencer y eliminar al oponente, sino de alcanzar un honorable armisticio que no provoque un resultado en forma de vencedores y vencidos. Esta es una carrera de fondo con obstáculos en cada esquina; será ganada por el feminismo porque tiene la razón de su parte, pero lo hará con marcha constante, buen ritmo y esperanza sólida en los resultados.

Mientras tanto, se corre el riesgo de tener dos idiomas: uno para uso exclusivo de juristas, políticos, periodistas mentalizados y para su empleo en las Cámaras y en reuniones y documentos oficiales, mientras en la calle, en la vida familiar, en las conversaciones ordinarias, en la ciencia y en la cultura, en el cine y en el teatro, en la poesía, en la novela, en las demás artes y en el mundo de la cultura en general, se habla y se escribe de otro modo. Puede que la cultura y las artes evolucionen e incorporen el empleo de masculinos y femeninos al modo como se hace ahora en ciertos círculos, pero no parece que vaya a suceder a corto plazo $^{26}$.

${ }^{23}$ Lledó Cunill, E.: Importancia del uso del lenguaje en el Derecho..., ob. cit., pp. 3-5.

${ }^{24}$ Ibidem, p. 6.

${ }^{25}$ Ganándose la réplica, dos años más tarde, del movimiento femenino revolucionario en forma de Declaración de los Derechos de la Mujer y de la Ciudadana, de Olympe de Grouges.

${ }^{26}$ Incluso puede vaticinarse con un mínimo margen de error que se producirá un movimiento de signo inverso a favor de la masculinización de un elevado número de términos, especialmente relativos a profesionales con desinencia — $a$, la cual, aunque sea en otros ámbitos y no siempre, tiene connotación femenina; es el caso de las denominaciones economista, jurista, geriatra, tecnó- 
En fin, este trabajo me ha proporcionado la oportunidad de conocer la dedicación de ya bastantes personas a la doble tarea de denuncia del sexismo y del androcentrismo en el uso del lenguaje y en la elaboración de fórmulas que, al menos, lo mengüen.

\section{APLICACIÓN A LA CONSTITUCIÓN}

Tras este acaso demasiado extenso alegato introductorio, que seguramente tiene algo de autoexculpatorio, debo pasar a trabajar sobre nuestra norma suprema, que, precisamente por serlo, puede tener un efecto reclamo (o efecto contagio) para otras normas.

$\mathrm{Y}$ es oportuno comenzar evocando, siquiera sea muy brevemente, que la transición política del régimen de Franco Bahamonde al régimen democrático significó la apertura en los órdenes social, cultural y político, así como el inicio en unos casos y la aceleración en otros de la incorporación de la mujer a todos esos ámbitos, desde la Universidad hasta la política, pasando por las profesiones más acreditadas (medicina, judicatura) y por el mundo de la cultura en su más diversas manifestaciones (novela, teatro, cine, periodismo, negocios, deporte).

La Constitución española fue redactada en unos 16 meses y colaboraron en ella un buen puñado de intelectuales (no solo juristas), dentro y fuera de las Cámaras. No faltaron mujeres notables que influyeron en el cambio de régimen. Y esa presencia e incidencia se incrementó durante los años siguientes hasta la entrada del nuevo siglo y milenio. La Ley de Igualdad ha significado la institucionalización jurídica de la igualdad de géneros, con derechos y obligaciones paritarios, bien que con las lógicas diferencias entre el Derecho privado y el Derecho público.

Vista la Constitución cuarenta años después, es fácil, demasiado fácil, el reproche de mediocridad que ahora se le hace. No sé si hoy podría escribirse mejor, pero sí, desde luego, de forma diferente; y a buen seguro podrá decirse lo mismo, en su momento, sobre el lenguaje de las reformas constitucionales que ahora se auspician y también, de llevarse a efecto, el de un texto constitucional de nuevo cuño que otros proponen. Pero siempre reflejará el estado de los intereses, fuerzas, conflictos y consensos convergentes en el momento de la redacción, aunque sea para superarlos. Porque, como dice M. A. Quintanilla, aunque la

crata, cineasta... para que su pronunciación y escritura pase también a ser doble: juristo, cineasto... No hay nada que oponer ni técnica, ni jurídica ni políticamente; pero, sumado a todo lo anterior, acaso sí estéticamente. 
ciencia sea difícilmente neutral en su origen dada la dependencia de los usos lingüísticos respecto de los valores, puede serlo en sus resultados ${ }^{27}$.

Pues bien, esta mi contribución a la conmemoración del $40 .^{\circ}$ aniversario de nuestro texto fundamental es un ensayo de reescritura de una buena porción de sus preceptos (concretamente de su Preámbulo y de los artículos primero a 29) procurando superar el androcentrismo de la redacción que salió de los talleres constitucionales en 1978, cuando aún no había iniciado su andadura dicho movimiento reivindicativo o andaba en sus primeros y no muy recios escarceos.

Su propósito es, por tanto, enhebrar soluciones en los términos explicados hasta aquí corrigiendo meramente la dicción literal de los preceptos allá donde ésta obedezca al patrón tradicional masculino. Sin embargo, alguna vez, en el texto o en notas, he cedido a la tentación de ampliar la corrección lingüística y estilística cuando el texto original es más oscuro o menos satisfactorio, y aun he cedido excepcionalmente a la tentación de hacer alguna corrección jurídica puntual cuando el texto me ha parecido menos defendible; con lo que no hago sino continuar los apuntes críticos razonados que hago en varias publicaciones ante la falta de precisión lingüística o jurídica del constituyente en varios pasajes ${ }^{28}$, sobre todo a la hora de nombrar los sujetos de los distintos derechos.

Por ejemplo, enlazando con lo dicho en páginas superiores, encontramos en la Constitución algunas propuestas que son decisiones, la que, conforme al artículo 62.e), hace el Presidente del Gobierno al Rey para nombramiento o separación de los miembros del mismo; y alguna solicitud que es una exigencia, como la de convocar un referendo de reforma constitucional en materias en las que el propio texto fundamental no lo requiere como obligatorio (artículo 167.3). En ambos casos los plasmó así el constituyente por deferencia con la Corona, puesto que es el Rey o, en su caso, la Reina quien ha de culminar dichos actos expidiendo los correspondientes decretos (con refrendo del Presidente del Gobierno). Qué duda cabe, por tanto, que el lector de textos jurídicos —en nuestro caso, constitucionales - ha de estar siempre atento no solamente a su letra, sino también a su contexto y espíritu para no errar en su comprensión.

De otra parte, debemos mirar a los lados y hacia atrás para hacernos cargo del entorno. Entonces advertiremos algo que, aunque es un asunto lateral en este trabajo, no le es del todo ajeno. Me refiero a que, a poco que fijemos nuestra atención, advertiremos con cierta sorpresa que el idioma, el habla, ha repartido

27 Quintanilla, M. A., Voz «Ciencia», ob. y lug. cits.

${ }_{28}$ Cfr., por todas, mis Principios de Derecho Constitucional Español, Publicaciones de la Facultad

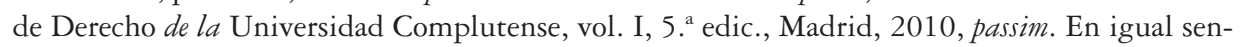
tido, Hernández-Gil, A., El cambio político español y la Constitución, ob. cit., pp. 348-350. 
los géneros con alguna equidad a la hora de dar nombre a los conceptos jurídicos y políticos. Tan es así que, si hiciéramos en el texto constitucional un recuento de términos alusivos a instituciones, garantías, derechos, etc., tarea para la que me falta paciencia, habría más femeninos que masculinos o andarían parejos. Yo no digo que el constituyente lo haya hecho dando intencionadamente preferencia al género femenino; sería un disparate; eso ni se planteó ni entraba en la imaginación del constituyente español (ni en las de ninguno otro de la época: Grecia, Portugal...). La respuesta es mucho más sencilla: el idioma castellano es así.

En efecto, si, como mero ejercicio práctico algo más fácil que el antes aludido y sin pretender elevar su resultado a categoría, hacemos dicha experiencia con el Preámbulo constitucional, que es un texto breve y el primero que encontramos, observaremos que en él aparecen veinte términos femeninos ${ }^{29}$ y ocho masculinos $^{30}$, todos ellos de significado positivo, como, salvo excepción, es normal en un texto constitucional.

$\mathrm{Y}$ es que, en las lenguas romances se suele nombrar los valores, las cualidades y las virtudes y algunos derechos mediante términos femeninos: libertad, igualdad, justicia, dignidad, solidaridad, garantía, participación, democracia, propiedad...; en tanto que los vicios y los defectos están más repartidos entre ambos géneros o los hay en mayor proporción del género masculino: delito, terrorismo, homicidio y asesinato, son masculinos, pero censura, banda armada, tortura y prevaricación son femeninos. Ya digo, en este terreno, el balance es de cierto equilibrio no desfavorable al género femenino.

Es evidente que lo que algunos preceptos necesitan es cambiar su contenido jurídico más que su dicción literal. Pero ese acaso sea objeto de un trabajo diferente. Mi compromiso aquí y ahora, al ofrecer la presente reflexión, es mostrar que no pocos preceptos constitucionales son susceptibles de mejorar lingüísticamente (en el sentido igualitario de los géneros) sin variar su contenido jurídico y sin perjuicio del idioma ${ }^{31}$. Y abrigo la esperanza de salir airoso del empeño e ilustrar su factibilidad para sucesivos momentos y proyectos normativos.

El propio texto constitucional ofrece varios ejemplos de cómo se puede formular principios y valores y regular derechos sin necesidad de utilizar vocablos significados por su género. Pero ninguno como el artículo 20, tan central

29 Son los siguientes: Nación, justicia, libertad, seguridad, soberanía, convivencia, Constitución, ley, democracia, voluntad popular, España, nación, cultura, tradición, lengua, institución, economía, calidad de vida, sociedad democrática avanzada y cooperación.

30 Hemos anotado: cuantos, orden económico y social, Estado, Derecho, imperio (de la ley), españoles, pueblos, pueblo español, derechos y progreso.

31 Aunque me temo que, por un tiempo, sea laboriosa su memorización (¡ay, de los opositores!). 
en el sistema de derechos y de redacción tan extensa. Estamos ante un claro ejemplo de equilibrio semántico en cuestión de género. No ocurrió así en todo el texto constitucional porque la cultura reinante en toda la Historia y todavía en 1977-1978 descansaba en un lenguaje tradicional en el que el género masculino era utilizado como genérico o ambivalente. Pero insisto: es bueno que el lector de hoy compruebe que no es ninguna hazaña encontrar fórmulas que, sin mengua de su precisión jurídica, sean más respetuosas con el cincuenta por ciento de la población.

Aunque la costumbre y la cultura ambiente hacen que no reparemos en la continua reiteración de expresiones tales como «los españoles» o «todos los españoles» y en que las españolas sean invisibles, yo intentaré evitar su desdoblamiento en las correspondientes parejas ( «los españoles y las españolas», «todos y todas»...), porque este cometido apenas requeriría la publicación de las presentes reflexiones ni la celebración de seminarios para certificar evidencias. Pero es que, además, he podido comprobar que estos desdoblamientos están desaconsejados por los expertos y por las guías de lenguaje no sexista, así que su uso debe ser excepcional, y excepcionalmente aparecerán aquí. Pues no se trata de que el texto constitucional quede meramente corregido, sino mejor. Aunque no siempre la corrección ideológica va pareja con la literaria — cuyo modelo, según se decía, era el Código Civil - debe procurar al menos un pasable buen decir.

Por eso resulta preferible alternar diversas fórmulas correctoras. A este respecto, me permito enunciar, de entrada, algunas de las técnicas que utilizo, unas propias y otras sugeridas por las guías existentes al efecto ${ }^{32}$ :

1. El uso no sexista del lenguaje no debe alejarse mucho del lenguaje común formal ni adoptar formas forzadas o artificiosas.

2. Hay que tener en cuenta la intención del texto y el público al que va dirigido.

3. Habrá ocasiones en que convenga emplear términos genéricos o polivalentes con los cuales solucionar no pocos problemas; términos que, por cierto, suelen ser de factura femenina aunque de significado ocasional genérico, como, por ejemplo, ciudadanía, nacionalidad, persona, etcétera, los cuales nos servirán para prescindir con ventaja de otros marcados por el género masculino, tales como españoles, todos o individuo.

4. A estos efectos, son igualmente útiles los pronombres indefinidos y así escribir, por ejemplo, quienes en vez de «los que»y «las que».

32 Unas son de mero sentido común y las utilizo desde hace años. Otras las he aprendido de los manuales y guías ya existentes, algunos de los cuales se citan en la bibliografía. 
5. En ocasiones serán inevitables algunos circunloquios operando sobre los verbos y algunos otros elementos de la redacción plasmada en el texto, pero no deben alargar demasiado las frases.

6. También da buen resultado mencionar alguna vez órganos, cargos y actividades en vez de sus titulares; por ejemplo:

- en lugar de decir juez o jueza, podemos utilizar el sintagma órgano judicial, y en lugar de Presidente o Presidenta, la Presidencia;

- en vez de el Rey y la Reina o los Reyes, se puede decir la Corona, si es pertinente, que no siempre lo será.

7. Entre dos textos igualmente válidos en términos jurídicos, debe ser preferido el más breve.

Puede parecer, según lo que antecede, que esta apuesta es una apología del sincretismo, pero en ella hay más bien una cierta dosis de prudencia para mantener una permanente y vigilante actitud crítica que tenga al mismo tiempo la suficiente flexibilidad como para variar de criterio a poco que el texto constitucional se resista a una de las operaciones indicadas.

La conclusión no puede ser otra que la de serenidad, confianza en la validez de la reivindicación, madurez en la reflexión, suerte en la determinación, buenos lingüistas, discusión serena y una mezcla de audacia y equilibrio. Lo cual significa ancha vía para acogerse a cuantos giros sean correctos en lugar de empeñarnos en usar únicamente la duplicación masculino-femenino u otra fórmula mecánica.

Indicaré por último que me he centrado en los primeros textos de nuestra norma suprema, justo los que abarcan el Preámbulo, el Título Preliminar y parte del Título I, concretamente los artículos 10 a 29; es decir, termino donde termina la regulación constitucional de los derechos fundamentales y de las libertades publicas. Lo he decidido así por dos motivos: primero, porque no es mal acuerdo comenzar por el principio, y, en segundo término, porque dichos textos, que tratan de los valores, principios, personas y derechos, constituyen un ámbito en el que podemos encontrar abundantes ocasiones para poner a prueba este ensayo $^{33}$.

33 Hernández-Gil, en su obra ya citada, pp. 348 y ss., hace no pocas consideraciones sobre la redacción del texto constitucional, por lo general muy acertadas. Pero son, según el mismo autor las denomina, «puntualizaciones técnico-estilísticas» y ninguna de las cuales se refiere al «estilo» masculino ambivalente que aquí tratamos. 


\section{PREÁMBULO}

La redacción de esta pieza muy positivamente valorada en círculos jurídicos fue encargada al Partido Socialista Popular para así compensarlo de no haber podido intervenir en la Ponencia Constitucional ni en la Comisión Mixta final. Curiosamente adopta dicciones diferentes a las del texto articulado para referirse a ideas similares y, por lo que respecta al objeto acotado en este ensayo, hay en él, pese a su fama de bien escrito, dos expresiones insertas en los párrafos primero, cuarto y quinto que requieren atención.

\section{PÁRRAFO PRIMERO}

Texto actual: «La Nación española, deseando... promover el bien de cuantos la integran...»

La frase «cuantos la integran» referida a la Nación española permite, a mi juicio, una operación mínima: sustituir «cuantos» de muy diversas formas, como, por ejemplo, «quienes», «las personas que» o «cuantas personas». Me inclino por la última solución porque se separa menos del texto inicial.

Texto propuesto: «La Nación española, deseando... promover el bien de cuantas personas la integran...».

\section{PÁRRAFO CUARTO}

Texto actual: «Proteger a todos los españoles y pueblos de España...»

Este párrafo hace de «todos los españoles», el objeto o complemento directo del verbo proteger. Las expresiones «todos los españoles»y «los españoles» son muy frecuentes, en el texto constitucional y tienen el mismo alcance, pues, aunque «todos» enfatiza más, no añade ni una unidad a la otra locución, que no admite excepción alguna. También en el presente párrafo podemos barajar varias fórmulas que sustituyan ventajosamente a la empleada por el constituyente y eviten, al mismo tiempo, excesivas reiteraciones. Sean, por ejemplo,

a) "a cuantas personas integran la Nación y a los pueblos de España»;

b) «a todas las personas y pueblos de España», que resulta preferible a mi entender por más breve e igualmente precisa.

Texto propuesto: «Proteger a todas las personas y pueblos de España».

PÁRRAFO QUINTO:

Texto actual: «Promover el progreso de la cultura y de la economía para asegurar a todos una digna calidad de vida». 
De nuevo nos encontramos con el masculino genérico «todos». En este caso, para no repetir la solución anterior, podemos optar por suprimirlo sin que el texto se resienta; antes al contrario, gana literariamente.

Texto propuesto: "Promover el progreso de la cultura y de la economía para asegurar una digna calidad de vida».

No son rectificables las expresiones «todos los pueblos» ni «el pueblo español», de los párrafos séptimo y octavo porque «pueblo» no tiene alternativa, como tampoco, en femenino, «nación española».

\section{TÍTULO PRELIMINAR}

El artículo primero no ofrece términos ni expresiones rectificables por el género empleado.

\section{ARTÍ́CULO 2. ${ }^{\circ}$}

Texto actual: La Constitución española se fundamenta en la indisoluble unidad de la Nación española, patria común e indivisible de todos los españoles».

Este precepto suscita la dificultad del género masculino, sobre todo por estar seguido de otro similar, lo cual hace muy forzado evitar, al menos en uno de ellos, la dicción de moda: «Todos los españoles y todas las españolas». La redacción del precepto bien podría ser la siguiente:

Texto propuesto: «La Constitución se fundamenta en la indisoluble unidad de la Nación española, patria común e indivisible de todos los españoles y todas las españolas...».

\section{ARTÍ́CULO 3}

\section{Apartado 1}

Texto actual: «El castellano es la lengua española oficial del Estado. Todos los españoles tienen el deber de conocerla y el derecho de usarla».

$\mathrm{Al}$ contrario del precepto anterior, este admite una operación que ya hemos hecho: prescindir del vocablo «todos» sin que sufra el significado jurídico, aunque nos obliga a alterar un tanto la redacción del precepto sustituyendo el deber de los españoles por deber cívico:

Texto propuesto: «El castellano es la lengua española oficial del Estado. Conocerla es un deber cívico y usarla un derecho». 


\section{ARTÍCULO 7}

Texto actual: Los sindicatos de trabajadores y las asociaciones empresariales...»

Debemos encontrar una solución al empleo del masculino genérico «trabajadores». Si no lo queremos duplicar con «trabajadoras», caben dos fórmulas: a) Dejar únicamente «los sindicatos» dando por sobreentendidas qué personas son las sindicadas puesto que felizmente se ha superado la verticalidad sindical franquista. b) Sustituir «de trabajadores» por «laborales» buscando así el paralelo con la expresión «asociaciones empresariales» que el propio precepto emplea.

Más sencilla es la primera, y más simétrica la segunda. Prefiero la sencillez:

Texto propuesto: «Los sindicatos y las asociaciones empresariales...».

\section{ARTÍ́CULO 9}

Del artículo 8 no hemos de ocuparnos, y del artículo 9, solamente hay que atender los apartados primero y segundo.

\section{Apartado 1}

Texto actual: «Los ciudadanos y los poderes públicos están sujetos a la Constitución y al resto del ordenamiento jurídico...»

La expresión inicial «los ciudadanos» puede ser sustituida por «todas las personas» porque, aparte de la cuestión de género, es bien cierto que también están sometidos al Ordenamiento jurídico, aunque con matices, quienes, aun no teniendo la ciudadanía española, tienen en España su residencia o están en ella de vacaciones o de paso. Los matices se dilucidan después, pero, en principio, nadie que pise suelo español tiene licencia para incumplir el ordenamiento. Por otra parte, el empleo de la voz «todas» para referirlo a las personas invita a decir otro tanto de los poderes públicos, con lo que nos quedaría: «Todas las personas y todos los poderes públicos están sujetos...»

En este caso, «están sujetos» referido a diferentes sujetos de la oración, valga el juego de palabras, es aceptable como masculino genérico. Pero también se puede buscar la solución cambiándolo por «sujeción» y alterando el orden del enunciado. A mi parecer, resulta preferible esta segunda fórmula.

Texto propuesto: «La sujeción a la Constitución y al resto del ordenamiento jurídico alcanza a todas las personas y a todos los poderes públicos».

Apartado 2

Texto actual: «Corresponde a los poderes públicos promover las condiciones para que la libertad y la igualdad del individuo y de los grupos en que se integra 
sean reales y efectivas; remover los obstáculos que impidan o dificulten su plenitud y facilitar la participación de todos los ciudadanos en la vida política, económica, cultural y social».

Este apartado segundo, tan prestigiado razonablemente por la doctrina, no escapa a una parcial reconsideración de su lenguaje de género al hablar de la libertad y la igualdad «del individuo» y de la participación de «todos los ciudadanos».

a) Consideraciones sobre el primer escollo: a.1) llama la atención la diferencia empleada por el constituyente entre el singular individuo y el plural grupos, cuando es muy evidente que debería haber mantenido el plural en ambos términos. a.2) Centrándonos en nuestro objetivo, el sintagma «del individuo» referido a la libertad y a la igualdad bien puede trocarse por un adjetivo (individuales o personales); de las dos maneras, además, se gana en elegancia expresiva. b) Como la expresión «libertades individuales» es tradicional en Derecho constitucional, podemos preferirla aquí. Sin embargo, el verbo «integrar(se)» quedaría sin sujeto. Por eso, de nuevo hemos de recurrir al comodín «de las personas» con lo que quedaría la siguiente redacción parcial: «... para que la libertad y la igualdad de las personas y de los grupos en que se integran...».

En cuanto al segundo escollo, dado que no solo los ciudadanos pueden participar en la vida económica, cultural, social e incluso política, la dicción del artículo resulta indebidamente masculina e imprecisa, admitiendo, a mi entender, un ajuste que sea más breve y prescinda de la locución incómoda: «.. y facilitar la participación en la vida política, económica, cultural y social».

Después de estos dos retoques, la nueva redacción íntegra de este apartado sería:

"Corresponde a los poderes públicos promover las condiciones para que la libertad y la igualdad individuales y de los grupos sean reales y efectivas; remover los obstáculos que impidan o dificulten su plenitud y facilitar la participación en la vida política, económica, cultural y social.»

\section{TÍTULO I: DE LOS DERECHOS Y DEBERES FUNDAMENTALES}

Pese a que yo suelo poner reparos al apartado 1 del artículo 10 en relación con el artículo 1.1, o viceversa, no son relevantes para nuestra presente preocupación. 
6.1 Capítulo I: De los españoles y los extranjeros (Rúbrica propuesta: Nacionalidad y extranjería)

\section{ARTÍCULO 11}

\section{Apartado 2}

Texto actual: «Ningún español de origen podrá ser privado de su nacionalidad».

La locución «ningún español» puede ser duplicada por «y ninguna española» Utilizaré la duplicación referida únicamente como último recurso (por ejemplo, en el apartado siguiente). En este caso, sustituiré «ningún español» por un simple «a quien»y acomodando el resto mediante una oración pasiva refleja, que tanto abunda en el texto constitucional y a la que tanto recurriremos en el presente escrito. Sinceramente me gusta más el texto actual, que es breve y elegante, pero no se corresponde con el objetivo que perseguimos.

Texto propuesto: "No se podrá privar de la nacionalidad española a quien la tenga de origen ${ }^{34}$.

\section{Apartado 3}

Texto actual: «En estos mismos países, aun cuando no reconozcan a sus ciudadanos un derecho recíproco, podrán naturalizarse los españoles sin perder su nacionalidad de origen».

La redacción de este tercer apartado es ciertamente complicada, con un amplio hipérbaton que desplaza el sujeto de la frase hasta casi el final. Por eso y para sortear los sintagmas «sus ciudadanos»y «los españoles», se necesita el servicio de un circunloquio. Pero aun así resulta difícil evitar el binomio «españoles y españolas». El resultado de la operación es la siguiente propuesta:

Texto propuesto: "Aunque estos países no reconozcan la reciprocidad, los españoles y las españolas podrán naturalizarse en ellos sin perder su nacionalidad de origen» ${ }^{35}$.

\section{ARTÍCULO 12}

Breve artículo que admite un pequeño cambio, dentro de esa misma brevedad, prescindiendo del sintagma los españoles por resultar fácilmente sobreentendido:

Texto actual: «Los españoles son mayores de edad a los 18 años».

Texto propuesto: «La mayoría de edad se alcanza a los 18 años».

34 Aunque creo preferible la redacción indicada, caben otras similares; por ejemplo: «Nadie puede ser privado de la nacionalidad española si la tiene de origen». «Nadie que tenga de origen la nacionalidad española puede ser privado de ella».

35 De nuevo cabe otra fórmula, como: «Aunque estos mismos países no tengan reconocida la reciprocidad, los españoles y las españolas podrán naturalizarse en ellos sin perder su nacionalidad de origen». Pero creo preferible la reflejada en el texto. 


\section{ARTÍCULO 13}

\section{Apartado 1}

Texto actual: «Los extranjeros gozarán en España de las libertades públicas que garantiza el presente Título...»

La expresión «Los extranjeros» admite su relevo por la perífrasis «quienes tengan nacionalidad extranjera», o mejor, «quienes no tenga nacionalidad española».

Texto propuesto: "Quienes no tengan nacionalidad española gozarán de las libertades públicas que garantiza el presente Titulo...

Apartado 2

Texto actual: «Solamente los españoles serán titulares de los derechos reconocidos en el artículo $23 \ldots »$

Podemos repetir la fórmula, adaptándola, del apartado anterior quedando el precepto del modo siguiente:

Texto propuesto: «Solamente quienes tengan nacionalidad española serán titulares de los derechos reconocidos en al artículo 23...».

\section{Apartado 4}

Texto actual: «La ley establecerá los términos en que los ciudadanos de otros países y los apátridas podrán gozar del derecho de asilo en España.»

La expresión «... los ciudadanos de otros países y los apátridas» no tienen fácil recambio que sea breve y claro, como es exigible a todo precepto. Acaso pudiera valer la supresión de algunas palabras, concretamente «en España», que no añaden nada, y el cambio de algunas otras, así como de su orden actual. Toda una reconstrucción del precepto, que quedaría con la siguiente dicción, no inferior técnicamente a la original:

Texto propuesto: «La ley establecerá los términos en que se reconoce el derecho de asilo para las situaciones de extranjería y de apatridia».

\subsection{Capítulo II: Derechos y libertades}

\subsubsection{ARTÍCULO 14}

Texto actual: «Los españoles son iguales ante la ley...»

De nuevo, la centralidad de este precepto invitaría a subrayar la igualdad nombrando expresamente los dos géneros. Pero el hecho inconcuso de que la igualdad alcanza no solo a quienes tienen nacionalidad española, hace preferir una dicción más inclusiva:

Texto propuesto: "Todas las personas son iguales ante la ley...». 
6.2.2 Sección 1.a: De los derechos fundamentales y de las libertades publicas ARTÍCULO 15

\section{Punto primero}

Texto actual: «Todos tienen derecho a la vida y a la integridad física y moral, sin que, en ningún caso, puedan ser sometidos a tortura...»

No es necesario recordar la polémica entre científica e ideológica, pero no gratuita, que acompañó a las primeras palabras del primer punto de este precepto. Seguramente lo más apropiado es utilizar de nuevo la clásica oración pasiva refleja se reconoce.

Pero esto obliga a cambiar también algunas de las palabras que siguen para mantener la concordancia. Cabe optar por la dicción más en línea con el comienzo:

«...sin que nadie, en ningún caso, pueda ser sometido...; o bien por esta otra ligeramente diferente: "Nadie, en ningún caso, puede ser sometido... Aunque, a nuestros efectos, valen las dos, me inclino por la segunda.

Texto propuesto: "Se reconoce el derecho a la vida y a la integridad física y moral. Nadie, en ningún caso, puede ser sometido a tortura...».

El resto del artículo queda igual, sin que proceda comentar la vigencia, todavía, de la pena de muerte, aunque sea de cumplimiento improbable ${ }^{36}$.

ARTÍCULO 16

\section{Apartado 1}

Texto actual: «Se garantiza la libertad ideológica, religiosa y de culto de los individuos y las comunidades...»

Debemos despejar, en la redacción actual, una duda inicial, que se desdobla en varias tras la lectura de todo el artículo:

a) ¿Se trata de tres libertades o de una sola con tres vertientes.

b) El precepto añade inmediatamente el límite del orden público en las manifestaciones de estas libertades; a mi juicio, el culto es precisamente eso: una manifestación de esta libertad o libertades y no una libertad autónoma y diferente de ellas.

36 Por no perturbar los argumentos atinentes a nuestro propósito, traigo a nota la deficiente técnica del texto vigente al desdoblar la integridad personal en física y moral con manifiesto olvido de la integridad psíquica, laguna que denuncié hace más de treinta años en mis Principios de Derecho Constitucional Español y que el Tribunal Constitucional se ha visto obligado a colmar mediante una interpretación extensiva del adjetivo moral. 
c) El apartado segundo excluye el culto y engloba en «su», adjetivo singular, la ideología, la religión y las creencias.

d) Y el siguiente utiliza los sintagmas «confesión» (en singular y en plural) y «creencias religiosas», ambas claramente referidas a la libertad religiosa (o a la vertiente religiosa de esta libertad).

e) Tan variada terminología más perturba que aclara el contenido preceptivo del artículo y, consiguientemente, nuestra labor. La doctrina mayoritaria ha acuñado otra denominación pretendidamente genérica que las englobe como especies suyas: la libertad de conciencia.

f) Pero además hemos de sustituir los sintagmas «de los individuos»y «[de] las comunidades» y para ello podemos utilizar dos adjetivos: individuales en el primer caso y comunitario en el segundo. Podemos acogernos de esa denominación genérica (libertad de conciencia) para interpretar que estamos ante una sola libertad, lo cual solo exige retocar mínimamente el inicio del precepto, que queda de modo bastante parejo al texto oficial.

Texto propuesto: «Se garantiza la libertad ideológica, religiosa y de culto individual y comunitario...».

\section{ARTÍCULO 17}

\section{Apartado 1}

También el presente artículo utiliza en su apartado primero expresiones que pueden mantenerse en este ejercicio de revisión: «toda persona», «nadie». Acaso sea más expresivo decir «todas las personas», pero, conforme al principio de intervención mínima y puesto que el cambio no hace ganar gran cosa, puede seguir con su propia redacción.

Apartado 2

Texto actual: «La detención preventiva... el detenido deberá ser puesto en libertad...»

La frase «el detenido deberá ser puesto en libertad...» puede ser mejorada desde el punto de vista aquí adoptado. Conforme a los criterios seguidos hasta ahora, debería decir:

«La persona detenida deberá ser puesta en libertad...». 
Apartado 3

Texto actual: «Toda persona detenida... no pudiendo ser obligada a declarar. Se garantiza la asistencia de abogado al detenido en las diligencias policiales y judiciales...»

Comienza también este apartado con la expresión «toda persona» y añade de forma concordante: «no pudiendo ser obligada a declarar». En cambio, acaso por evitar la reiteración, el constituyente escribió más adelante «la asistencia de abogado al detenido», lo que obliga a buscar una dicción diferente de igual significado para obviar los dos términos masculinos. Veamos:

a) Donde dice «asistencia de abogado» puede escribirse «asistencia letrada»;

b) Seguramente lo mejor que puede hacerse con la expresión «al detenido» es suprimirla por obvia, o bien, lo que me parece preferible, suprimirla colocando el pronombre «le» delante del verbo «garantiza».

Haciéndolo como indico, este segundo punto del apartado tercero podría adoptar la redacción que sigue: «Se le garantiza la asistencia letrada...»

No me gusta, sin embargo, porque hay una cesura entre el primer punto y el segundo. Aunque no impide la correcta comprensión del precepto, podemos mejorarla uniendo los dos puntos del apartado y acudiendo a un gerundio, muy útil en esta ocasión: garantizándosele. Finalmente, buscando una redacción más nítida, adelanto la frase final y cambio alguna coma. Como se puede apreciar, son varias las alteraciones propuestas, pero formales y leves, además de que mejoran la redacción y ayudan a conseguir nuestro objetivo:

Texto propuesto: "Toda persona detenida... no pudiendo ser obligada a declarar y garantizándosele, en los términos que la ley establezca, la asistencia letrada en las diligencias policiales y judiciales».

Es necesaria o conveniente todavía una precisión respecto del pronombre «le» unido al gerundio empleado. $\mathrm{Y}$ es preciso por el muy difundido leísmo existente en España, conforme al cual podría tomarse dicho pronombre como sustitutivo de «a él» (al detenido). Sin embargo, no hay tal, sino que hace referencia a «toda persona», que es el sujeto que hemos empleado al principio del precepto, de tal manera que si es una mujer quien se encuentra en tal situación, también le conviene la fórmula adoptada: garantizándosele la asistencia letrada, etcétera.

\section{ARTÍ́CULO 18}

Las correcciones que cabe hacer en este artículo son reiteración de lo dicho en preceptos anteriores. 
Apartado 2

Texto actual: «El domicilio... Ninguna entrada o registro podrá hacerse en él sin consentimiento del titular o resolución...

Basta con sustituir la expresión masculina «del titular» por de su titular.

Texto propuesto: «... Ninguna entrada o registro podrá hacerse en él sin consentimiento de su titular».

\section{Apartado 4}

Texto actual: «La ley limitará el uso de la informática para garantizar el honor y la intimidad personal y familiar de los ciudadanos y el pleno ejercicio de los derechos».

Como se trata de «garantizar el honor y la intimidad personal y familiar», no es necesario especificar que lo es «de los ciudadanos», expresión que, por lo demás, es inexacta, porque también se garantizan tales derechos a otros sujetos diferentes, como hemos viso en preceptos anteriores y habremos de seguir viendo. Estando claro lo anterior, resulta más apropiado eliminar dicha expresión.

Ahora bien, en tal caso, como hemos prescindido del sujeto de tales derechos por obvio, las dos palabras finales «sus derechos», aunque comprensibles, deben ser mínimamente retocadas (los derechos) para coordinarlas con la anterior corrección. Por tanto, la redacción que se propone de este apartado es la siguiente:

Texto propuesto: "La ley limitará el uso de la informática para garantizar el bonor y la intimidad personal y familiar y el pleno ejercicio de los derechos».

\section{ARTÍCULO 19}

Texto actual: «Los españoles tienen derecho a elegir libremente su residencia y a circular por el territorio nacional.

Asimismo, tienen derecho a entrar y salir libremente de España...».

En primer lugar, debemos corregir el sujeto, puesto que es realmente más amplio que el señalado (los españoles). Pero esto requiere, a su vez, modificar el segundo párrafo para evitar la discordancia. Conseguimos ambos objetivos acudiendo nuevamente a una forma verbal se reconoce.

Además, el primer párrafo resulta excesivamente redundante de que estamos ante un derecho de libertad, extremo bien sabido y que no necesita ser tan remachado con tres términos que apuntan a la misma idea: derecho de elegir libremente. Se puede prescindir de la última palabra, como igualmente, por innecesaria, de la coma que sigue al término «asimismo» con el que comienza el segundo párrafo. 
Propuesta inicial: «Se reconoce el derecho a elegir residencia y a circular por el territorio nacional.

Asimismo se reconoce el derecho a entrar y salir libremente de España... "

Sin embargo, parece innecesario emplear dos párrafos si sus correspondientes facturas son tan iguales. Con su unión mejora el conjunto:

Texto propuesto: «Se reconoce el derecho a elegir residencia y a circular por el territorio nacional, así como el derecho a entrar y salir libremente de España...».

ARTÍCULOS 20, 21 y 22

El artículo 20 regula un bloque temático central en todo sistema democrático y lo hace con extensión e intensidad. Aunque su redacción actual es susceptible de varios matices jurídicos, no sucede lo mismo en lo atinente a nuestro trabajo, como ya hemos adelantado. Y no necesita retoques precisamente porque habla solo de derechos y garantías evitando los sujetos. Así que nada obsta a mantenerlo como dispuso el constituyente. Y otro tanto hay que decir de los artículos 21 y 22.

\section{ARTÍCULO 23}

Apartado 1

Texto actual: «Los ciudadanos tienen el derecho a participar en los asuntos públicos, directamente o por medio de representantes, libremente elegidos en elecciones periódicas por sufragio universal».

Más difícil remedio tiene este apartado, igualmente importante pues que reconoce el derecho de participación política tanto directa como representativa. La dificultad comienza con la identificación del sujeto de este derecho. Primeramente debemos sustituir la locución «los ciudadanos» porque es masculina y porque es inexacta, como se comprueba en el artículo 13, que reconoce a los extranjeros una titularidad reducida y condicionada. Se logra utilizando una vez más la fórmula «se reconoce el derecho», o bien, por variar, «se garantiza...» que es más enfático. No ocurre lo mismo, sin embargo, a la hora de sustituir ventajosamente la frase «representantes libremente elegidos en elecciones periódicas». Veamos.

El término «representantes», como participio de presente que es, aúna todavía los dos géneros. No se suele decir «representanta», pero tampoco podemos desconocer que hace ya tiempo que son utilizados los correspondientes femeninos en algunos participios similares, como presidenta, asistenta y dependienta; seguramente será cuestión de tiempo que termine diciéndose «representanta», si bien, hoy por hoy, «representantes» es correcto como masculino genérico ambivalente. 
Por otra parte, existe una clara redundancia ínsita en la locución «libremente elegidos», pudiendo ser reducida a este segundo vocablo, puesto que una elección no libre no es propiamente una elección. Pero el participio pasivo masculino que nos queda, «elegidos», exige, para ser sustituido o suprimido, variar el formato del precepto sin afectar a su contenido jurídico-político.

Además la redacción actual puede dar la impresión de que el sufragio universal se reconoce únicamente en la participación representativa. Ciertamente el sentido común desecha tal lectura, pero, si se considera conveniente, podría evitarse tal efecto alterando el orden de la actual redacción.

Por último, no puedo sino llamar la atención sobre la conjunción disyuntiva «»» que separa en el texto vigente ambas formas de participación cuando lo correcto es la copulativa « $y$ » puesto que se quiere afirmar el reconocimiento de las dos vías. En fin, como vemos, aunque la intelección de la frase no admite dudas, puede mejorarse su redacción: En consecuencia, el precepto puede adoptar el siguiente

Texto propuesto: "Se reconoce el derecho a la participación política directa y representativa en los asuntos públicos mediante elecciones periódicas, con sufragio universal en ambas vías».

\section{Apartado 2}

El apartado segundo podría unirse al anterior mediante una sencilla coma y una locución de enlace. Por ejemplo: así como el derecho a acceder... Sin embargo, ateniéndome al principio de intervención mínima, pueden quedar separados ambos apartados dejando el segundo con su redacción actual.

\section{ARTÍ́CULO 24}

\section{Apartado 1}

Este apartado nos da el trabajo casi hecho puesto que se inicia con una fórmula («todas las personas») que abarca los dos géneros. Aun así, es matizable. En efecto, llamo la atención sobre el término jueces, que se emplea también en el apartado siguiente.

a) Los jueces y tribunales es la denominación que da este apartado a la autoridad judicial en sus dos conformaciones: unipersonal y colegiada. Únicamente le sobra el artículo los, que masculiniza innecesariamente esa frase.

b) Juez ordinario predeterminado por la ley es la denominación adoptada por el apartado siguiente y tampoco es una expresión masculina, sino que, como en el caso anterior, equivale a Justicia, autoridad judicial ordinaria.

c) Por último, el artículo 17.2 adopta la expresión autoridad judicial. 
Cabe concluir, por tanto, que todas estas expresiones tienen un significado igual o muy similar: autoridad judicial, fórmula que resulta preferible por tanto

Apartado 2

Párrafo primero

Texto actual: «Asimismo, todos tienen derecho al Juez ordinario predeterminado por la ley, a la defensa y a la asistencia de letrado, a ser informados de la acusación formulada contra ellos... a no declarar contra sí mismos, a no confesarse culpables y a la presunción de inocencia».

Este párrafo vuelve al pronombre «todos» y algunas expresiones más que debemos traducir a un lenguaje más comprehensivo.

a) La frase «Asimismo todos tienen derecho» bien puede redactarse como continuación del apartado anterior, lo que se obtiene prescindiendo de «todos»; quedaría: «Asimismo tienen derecho», o, de modo más elegante, «Tienen asimismo derecho».

b) Respecto de la expresión «Juez ordinario predeterminado por la ley» ya he mentado su interpretación correcta ${ }^{37}$. Por eso, como es o puede parecer androcéntrica, escribiremos «autoridad judicial predeterminada por la ley».

c) Nos encontramos a continuación con «a la defensa y a la asistencia de letrado», cuya modelación no ofrece especial resistencia a ser redactado como «a la defensa y a la asistencia letradas», como hicimos en el artículo 17.3. Incluso se puede prescindir de la segunda «a la», quedando así: «a la defensa y asistencia letradas».

d) Lo más inmediato al leer la frase siguiente («a ser informados») es hacer como en el artículo 17: utilizar el pronombre personal les con el verbo igualmente en forma pasiva, pero refleja, quedando así: «a que se les informe», opción en la que el pronombre les ya no sustituye a todos porque ha sido suprimido.

e) Y, siguiendo el mismo orden literal del precepto, encontramos «de la acusación formulada contra ellos», que, con toda seguridad, no se resiente si salvamos el escollo de «ellos», para lo cual podemos optar por alguna de las siguientes variantes: 1) de la acusación que se les hace, 2) de la acusación que se les formula y 3) de la acusación de la que son objeto.

37 Si acudimos en busca de auxilio al título VI, «Del Poder Judicial», no quedaremos satisfechos porque, de una parte, siguiendo la tónica general de la Constitución, escribe con mayúscula los términos Jueces y Magistrados, lo mismo que Diputados y Senadores; también Juzgados y Tribunales, incluso Jurado. En cambio, escribe con minúsculas poder judicial, que es el nombre propio de uno de los tres poderes clásicos y básicos del Estado. 
Más elegante es la última, y más aún si reducimos «de la que» por «de que», con lo que resultaría «de la acusación de que son objeto».

f) Todavía nos queda otra expresión que debemos corregir: «a no declarar contra sí mismos». No es difícil y tenemos a nuestra disposición dos variantes al menos: ora suprimir la palabra «mismos», que no añade significado alguno a «contra sí», sino solo énfasis; ora utilizar un giro castizo, pero no vulgar ni, menos aún, erróneo: «en contra suya». Tendríamos entonces «contra sí»y «en contra suya».

El dictado final de este párrafo resulta de la integración de todas las variantes que hemos ido exponiendo y queda con la dicción literal que transcribo.

Texto propuesto: "Tienen asimismo derecho a la autoridad judicial predeterminada por la ley, a la defensa y asistencia letradas, a la información sobre la acusación que se les formula... a no declarar contra sí, a no confesarse culpables y a la presunción de inocencia».

Párrafo segundo

Texto actual: «La ley regulará los casos en que... no se estará obligado a declarar...»

La frase puede dar paso a otra enteramente coincidente pero con diversa factura: no será obligatorio declarar.

Texto propuesto: "La ley regulará los casos en que, por razón de parentesco o de secreto profesional, no será obligatorio declarar sobre bechos presuntamente delictivos».

\section{ARTÍCULO 25}

Apartado 1

Texto actual: «Nadie puede ser condenado o sancionado por acciones u omisiones...»

Únicamente presentan alguna dificultad los participios condenado y sancionado. Hay que modificar la forma verbal para evitarlos, para lo cual pueden ser utilizadas dos formas del verbo poder: el presente, que es la utilizada por el constituyente, o el futuro, que tiene frecuentemente en los textos normativos un significado imperativo (mandato o prohibición). El hecho de que de las dos maneras queda bien clara la prohibición me lleva a dejar el mismo término que emplea el texto constitucional. Por otra parte, hay que sustituir una conjunción (o) por otra $(n i)$, quedando así la línea inicial propuesta en contraste con la vigente.

Texto propuesto: «No se puede condenar ni sancionar a nadie por acciones $u$ omisiones...»

El resto del precepto seguiría con la redacción actual. 
Apartado 2

Texto actual: «Las penas... no podrán consistir en trabajos forzados. El condenado a pena de prisión que estuviere cumpliendo la misma gozará...»

Este extenso apartado ofrece dificultad únicamente en una frase intermedia transcrita que incluye el término «condenado» y que es innecesariamente redundante. No es preciso aclarar que, si alguien está cumpliendo pena de prisión, es porque ha sido juzgado y condenado, por lo que basta aludir al cumplimiento de la pena para entender la situación jurídica en que se halla. Se da la circunstancia, además, de que, abreviando así la frase, no solo obviamos el término condenado, sino que presenta la no poca ventaja de su mejor expresión jurídica y literaria.

Texto propuesto: "Quien estuviere cumpliendo pena de prisión gozará...»

\section{ARTÍCULO 27}

Este es seguramente el artículo más complejo de todos los que estamos tratando en esta ocasión, no solo por la prolijidad de las materias que regula, sino también porque se dan cita en él expresiones que requieren una cuidadosa atención.

\section{Apartado 1}

Texto actual: «Todos tienen derecho a la educación. Se reconoce la libertad de enseñanza».

Contrariando la disciplina autoimpuesta en este empeño, he de comenzar llamando la atención sobre un error de este apartado, que me lleva a contrariar su redacción y sentido. Se trata del cruce terminológico introducido por el constituyente llamando educación a la enseñanza y enseñanza a la educación ${ }^{38}$. La enseñanza o instrucción es un derecho y la educación una libertad. Por otra parte, aunque tiene más fuerza expresiva la fórmula «se garantiza», nos quedamos con «se reco-

38 Para no distraer al lector de la secuencia normal del texto, traigo a nota la explicación de lo dicho. En efecto, la enseñanza es transmisión de saberes, clásicamente llamada en España instrucción hasta el punto de haberse denominado así, en ciertas épocas, al Ministerio correspondiente. Y es a esta instrucción, a la transmisión de saberes y a la recepción de los mismos por el alumnado a lo que se tiene indiscutible derecho. En cambio, educación (del latín duco, ducere) significa etimológicamente conducir, guiar, dirigir, tarea que se realiza con consejos, advertencias, explicación sobre valores, análisis de conductas, recomendaciones, etcétera. He llamado la atención sobre este disparate desde la primera edición de mis Principios de Derecho Constitucional español (1985) con eco nulo en la doctrina y en los poderes públicos, que siguen utilizando la confusa terminología constitucional. En cambio, el Tribunal Constitucional, en alguna ocasión, como de pasada y sin continuidad, ha utilizado correctamente dichos términos. 
noce» porque es la utilizada en el texto constitucional. De esta manera se elimina el sujeto «todos», con lo que el apartado rezaría del siguiente modo:

Texto propuesto: «Se reconoce el derecho a la enseñanza y la libertad de educación».

Apartado 3

Texto actual: «Los poderes públicos garantizan el derecho que asiste a los padres para que sus hijos reciban la formación religiosa y moral que esté de acuerdo con sus propias convicciones».

Hemos de fijar nuestra atención en este apartado tercero porque habla de padres e hijos en el ejercicio de un derecho-libertad deslizando otro error, puesto que su sujeto, como el de todos los derechos del sistema educativo en su vertiente discente son los alumnos y los padres tienen su ejercicio tan solo durante la minoría de edad de estos como representantes legales suyos que son ${ }^{39}$.

Por lo que al sesgo masculinista del apartado se refiere, resulta verdaderamente difícil rectificarlo porque habría que prescindir de sus protagonistas, los alumnos y sus padres, sobre todo en el primer caso. Por eso, de una parte, puede aceptarse el empleo de la dualidad alumnos-alumnas, y, de otra, en cuanto a los padres, es preferible acudir al sintagma «sus representantes legales», que es incluso más preciso porque la condición de representante(s) legal(es) no solo es predicable también de los padres, sino que lo es en primerísimo lugar y de modo excluyente de cualesquiera otros, que solo pueden serlo en defecto de aquellos.

En fin, sobra el adjetivo propias referido a convicciones, puesto que, si no son lo primero, no son lo segundo. Pero lo dejamos estar porque no afecta al propósito de este ensayo.

Asumido todo lo anterior, el apartado rezaría como sigue:

Texto propuesto: "Los poderes públicos garantizan el derecho que asiste a los alumnos y a las alumnas, $y$, durante su minoría de edad, a sus representantes legales, a recibir la formación religiosa y moral que esté de acuerdo con sus propias convicciones».

39 De nuevo traigo a nota la explicación para no perturbar la fluidez del texto. Efectivamente, así como la libertad de educación del docente no le permite hacerlo en valores no compartidos por sus alumnos, por algunos de ellos o por los padres de estos durante su minoría de edad, tampoco los padres pueden imponer a su hijo mayor de edad (condición jurídica que se adquiere a los 18 años según el artículo 12 de la propia Constitución y que comporta la plena capacidad jurídica y de obrar) que se forme en un colegio, instituto o universidad contrarios a las propias convicciones de este. 
Apartado 4

No ofrece flancos a nuestro comentario ${ }^{40}$.

Apartado 5

Texto actual: «Los poderes públicos garantizan el derecho de todos a la educación, mediante una programación general de la enseñanza, con participación efectiva de todos los sectores afectados y la creación de centros docentes».

Este apartado ${ }^{41}$ incurre en una notable contradicción, puesto que dice que los poderes públicos garantizan el derecho a la educación mediante una determinada programación de la enseñanza.

a) Como la garantía de estos derechos no está en discusión, bien podemos prescindir de la reiteración que el precepto hace del derecho a la educación y de su garantía, con lo que, de paso, evitamos la contradicción señalada en el apartado primero y la palabra «todos».

b) Tampoco resulta nítida la función de la conjunción copulativa «y»al final del precepto, pues no se sabe si une la creación de centros docentes con la programación de la enseñanza o con la participación en ella de los sectores afectados. La falta de una coma que la anteceda sugiere esto segundo, pero la intelección del precepto nos inclina por la primera hipótesis. Es decir: la garantía consiste (o parece consistir) en la mentada programación general de la enseñanza y en la creación de centros docentes. Por eso conviene introducir una coma y el sintagma «así como» antes de «la creación de centros docentes».

Texto propuesto: «Corresponde a los poderes públicos realizar una programación general de la enseñanza con participación efectiva de los sectores afectados, así como la creación de centros docentes».

Apartado 7

Texto actual: «Los profesores, los padres y, en su caso, los alumnos intervendrán en el control y gestión de todos los centros sostenidos por la Administración...»

Este apartado comienza con unas palabras que nos plantean de nuevo la forma en que podemos evitar su androcentrismo: «Los profesores, los padres y, en su caso, los alumnos...» Estamos ante el típico ejemplo en el que, si nos dejára-

40 A no ser la confirmación de mi crítica al apartado primero, puesto que aquí se llama enseñanza a lo que es efectivamente enseñanza. No deja de sorprender que el constituyente utilice este término en el mismo artículo con dos significados no contrarios, pero sí contradictorios.

41 Reitera el derecho de todos a la educación, con lo que se vuelve al error inicial. 
mos llevar por la creciente tendencia actual, habríamos de decir: «Los profesores y las profesoras, los padres y las madres y, en su caso, los alumnos y las alumnas». Llegará el momento en que así se haga, si es que no ha llegado ya, pero creo que puede decirse mejor sin tantas parejas de términos. Se me ha sugerido utilizar los términos profesorado y alumnado, pero los padres no tienen término igualmente sustitutorio; y, el sintagma «representantes legales», no encaja bien con alumnado.

A mi juicio, el escollo puede salvarse con una perífrasis incluyente de todos los sujetos enunciados por el precepto y dejando igual el resto del apartado. Tal puede ser «las personas partícipes en el proceso educativo, sean docentes, discentes o sus representantes legales». Seguramente esta redacción no es una obra de arte literaria, pero cumple su función y no he hallado otra mejor.

La referencia a que los alumnos intervendrán «en su caso» queda obviada por la precisión que el propio precepto hace de que todos intervendrán «en los términos que la ley establezca», ya que en dichos términos deben estar incluidas las formas de intervención del alumnado. Por consiguiente, el apartado podría quedar redactado así:

Texto propuesto: "Las personas partícipes en el proceso educativo, sean docentes, discentes o sus representantes legales, intervendrán en el control y gestión de todos los centros sostenidos por la Administración...».

Apartados 8, 9 y 10

No necesitan reescritura a mi juicio.

\section{ARTÍCULO 28}

\section{Apartado 1}

Texto actual: «Todos tienen derecho a sindicarse libremente. La ley podrá limitar o exceptuar... y regulará las peculiaridades de su ejercicio para los funcionarios públicos...»

Los escollos que debemos salvar en este precepto son el sujeto del derecho de sindicación («todos») y la referencia a los «funcionarios públicos».

El primero no debería existir, pues es bien notorio que no todos son sujetos de este derecho; como ya hemos advertido al tratar del artículo 7 , en una democracia los sindicatos no son ni pueden ser verticales; por tanto, no son sujetos de este derecho los empresarios, ni tampoco quienes no están en el mercado de trabajo, como los rentistas o los escolares menores de edad. Por consiguiente, no es preciso sustituir el vocablo, sino redactar el inicio del apartado de modo genérico e impersonal: «Se reconoce el derecho de sindicación libre». 
Incluso podríamos prescindir de la palabra «libre» porque, si la sindicación no es libre, no puede ser objeto de un derecho, sino, en todo caso, de una obligación.

De otro lado, el precepto exceptúa impropiamente del ejercicio del derecho de huelga a las Fuerzas o Institutos armados y Cuerpos sometidos a disciplina militar. Impropiamente, digo, porque parece que trata a dichas instituciones como sujetos de un posible y diferenciado derecho de huelga en vez de decirlo de las personas pertenecientes a alguno de esos Institutos o Cuerpos, como hace correctamente el artículo 29.2 a tenor del derecho de petición. Sin embargo, la deficiente escritura de dicho pasaje no impide su correcta intelección.

Lo que resulta incómodo de solucionar es la mención de los funcionarios públicos porque no me decido a recurrir a la muy cacofónica expresión de «los funcionarios públicos y las funcionarias públicas». Pero bien mirado, de nuevo nos encontramos ante un error del texto constitucional porque en la Administración (en su sentido más amplio) trabajan personas que no tienen la categoría de funcionarios, como, por ejemplo, los contratados laborales a los que, sin embargo alcanza la excepción expresada en el precepto. Así que, en lugar de buscar palabras que sustituyan a funcionarios públicos, hemos de acogernos a una expresión polivalente, sean, por ejemplo, la Administración pública o la función pública. Me inclino por la segunda porque es de significado aún más amplio. De manera que podríamos redactar esa frase así: «La ley... regulará las peculiaridades de su ejercicio en el seno de la función pública.

En definitiva, el apartado primero puede adoptar una dicción literal que, a mi juicio, mejora la actualmente vigente:

Texto propuesto: «Se reconoce el derecho de sindicación libre». La ley... regulará las peculiaridades de su ejercicio en el seno de la función pública.

\section{Apartado 2}

Texto actual: «Se reconoce el derecho a la huelga de los trabajadores...»

Este segundo apartado trata del derecho de huelga, o «a la huelga», como gusta decir, cuyos sujetos son «los trabajadores». Aunque en el artículo 27.3 hemos empleado el binomio masculino-femenino, lo hemos hecho en tan escasas ocasiones hasta ahora que no es desdoro incluirlo de nuevo aquí y así ahorrarnos la búsqueda de su poco fácil sustitución. De manera que el precepto debería tener la siguiente redacción en contraposición a la actual:

Texto propuesto: «Se reconoce el derecho a la buelga de los trabajadores y (de las). trabajadoras...» 


\section{ARTÍCULO 29}

\section{Apartado 1}

Texto actual: «Todos los españoles tendrán derecho de petición individual y colectiva...»

El sujeto del derecho de petición es identificado en este precepto como «los españoles» exclusivamente. El propio Tribunal Constitucional lo definió como derecho uti cives $^{42}$, esto es, propio exclusivamente de los ciudadanos. Muy cicatera parecía esta interpretación literal. Y, en efecto, la Ley 4/2001, de 12 de noviembre, ha interpretado extensivamente la dicción constitucional reconociendo dicha titularidad a los extranjeros. Muchas razones hay para ello, pero hemos de ceñirnos a nuestro cometido y dejar solamente indicada esa interpretación amplia, como ha sucedido en otros varios preceptos constitucionales.

Asumiendo lo dicho, prefiero no sustituir el término «españoles» ni con «españoles y españolas» ni con «ciudadanos y ciudadanas» ni con «todos y todas», que es el binomio que menos me gusta. De manera que acudo de nuevo al verbo reconocer, que es garantía de acierto:

Texto propuesto: «Se reconoce el derecho de petición individual y colectiva...»

Apartado 2

Texto actual: «Los miembros de las Fuerzas o Institutos armados o de los Cuerpos sometidos a disciplina militar podrán ejercer este derecho...

En la redacción de este precepto, aun mejorando la mención a las Fuerzas o Institutos armados en comparación con de la que hace el artículo 28.1, no deja de incomodar la locución «los miembros». Aunque ya algunos emplean el binomio miembros-miembras, creo preferible redactar la sustitución de modo diferente, como, por ejemplo, «las personas pertenecientes...». Con lo que el precepto rezaría del siguiente tenor literal:

Texto propuesto: «La personas pertenecientes a las Fuerzas o Institutos armados o a los Cuerpos sometidos a disciplina militar podrán ejercer ese derecho...»

$* * *$

\section{SUMARIO REPERTORIO DE FUENTES}

Birdwnistell, R. L.: «Comunicación», en DSILL, D. L.: Enciclopedia de las Ciencias Sociales, edic. esp. Aguilar, Madrid, 1974, vol. 2, pp. 559 y ss.

${ }^{42}$ STC $161 / 1988$, FJ 5. 
Ferrater Mora, J.: Diccionario de Filosofía, Alianza Editorial, Madrid, 1979, voces «Lenguaje», vol. 3, pp. 1937-1941, y «Discurso», vol. 1, p. 843-846;

Gerth, H, y Wrigth Mills, C: Carácter y estructura social, edic. esp., Paidos, Buenos Aires, 1963.

Hernández-Gil, A.: El cambio político español y la Constitución, Planeta, Barcelona, 1982.

Lledó Cunill, E., y Guerrero Martín, C.: y Hablamos de leyes, Instituto de la Mujer (Ministerio de Igualdad), 2008.

Lledó CuniLl, E.: «Perspectiva de género en la comunicación e imagen corporativa», en la obra colectiva Nombrar a las mujeres, describir la realidad: la plenitud del discurso, Emakunde, Vitoria-Gasteiz, 2004, pp. 13-54.

Medina Guerra, A. M.: Manual del lenguaje administrativo no sexista, Universidad y Ayuntamiento de Málaga, 2002. 'http:/www.uce.es/cont/descargas/documento5682.pdf

Menéndez Menéndez, I.: Lenguaje administrativo no sexista, Instituto Andaluz de la Mujer, s.f. (¿2006?).

Parsons, T.: El sistema social, edic. esp., Revista de Occidente, Madrid, 1966.

Prieto de Pedro, J.: «Lenguaje jurídico y Estado de Derecho», Revista de la Administración Pública, Madrid, n. ${ }^{\circ} 140$.

Quintanilla, M. A.: Voz «Ciencia», en Diccionario de Filosofía Contemporánea, obra dirigida por él mismo, Sígueme, Salamanca, 1979.

Rocher, G.: Introducción a la Sociología General, edic. esp., Herder, Barcelona, 1973.

- Introducción a la Sociología General, edic. esp., Herder, Barcelona, 1973.

- Guía para el uso no sexista de lenguaje, Servicio de Publicaciones de la Universidad Autónoma de Barcelona, 2011.

- Uso no sexista del lenguaje administrativo, Ministerio de Asuntos Sociales. Instituto de la Mujer, 1993.

Resoluciones de la UNESCO 14.1 (1987), 109 (1989).

Recomendación de la UNESCO aprobada por el Consejo de Ministros (21-II-1990).

Recomendaciones para un uso no sexista del lenguaje, Unesco, París. http:/www.volensamerica.org/IMG/pdf/Mat_15_unesco-no-sexista.pdf

Orden Ministerial de 22-III-1995, por la que se establece la adecuación lingüística de los títulos académicos oficiales.

Ley Orgánica 3/2007, de 22 de marzo, para la Igualdad Efectiva de Mujeres y Hombres, principalmente sus títulos II y III. 


$$
\text { *** } *
$$

Title:

Wording of the Constitution in a non masculine slant.

\title{
Summary:
}

1. Introduction. 2. Law and Language. 3. Aplication to the Constitution. 4. Preamble. 5. Preliminary Part. 6. Part I: Concerning fundamental rights and duties. 6.1 Chapter I: Spaniards and Aliens. 6.2 Chapter II: Rights and Liberties. 6.2.1 Section 14. 6.2.2 Division I: Fundamental Rights and Publics Liberties.

\section{Resumen:}

El lenguaje es un componente esencial del Derecho. El Derecho y la justicia se expresan con palabras. Los lenguajes jurídicos habituales en las culturas históricas han coincidido siempre en su sesgo masculino. El presente trabajo es un ensayo de redacción de ciertos pasajes de la Constitución española (el Preámbulo y los artículos primero a 29) procurando superar su sesgo masculino sin cambiar su sustancia jurídica.

\begin{abstract}
:
Language is an essential component of the law. The law and the justice are expressed with words. The juridic languages have historically been expresed from the male slant. This is a trial of new wording of certain passages of the Spanish Constitution (the preamble and the articles 1 to 29) trying to overcome their male slant without changing the juridic substance.
\end{abstract}

Palabras clave:

Derecho, lenguaje, feminismo, lenguaje feminista.

Key words:

Law, language, feminisme, feminist language. 